\title{
DE VOLTA À TEORIA DA CURVATURA DA VARA: A DEFICIÊNCIA INTELECTUAL NA ESCOLA INCLUSIVA
}

\author{
Giovani Ferreira Bezerra* \\ Doracina Aparecida de Castro Araújo**
}

RESUMO: Este artigo propõe uma reflexão filosófica sobre a inclusão escolar de alunos com deficiência intelectual por meio de um exercício crítico-dialético, objetivando detectar as contradições do fenômeno estudado. Constatam-se concepções e práticas pedagógicas aparentemente inclusivas e democráticas, cuja essência, entretanto, leva à exclusão reiterada desses alunos, em razão de não atendê-los em suas necessidades cognitivas, nem admitirem nenhuma metodologia ou currículo diferenciados, necessários à sua aprendizagem. Conclui-se, assim, que a escola inclusiva, tal como se apresenta hoje, acaba tornando-se reacionária e pouco democrática, diferentemente da escola especial, que se revelava comprometida com o ensino dos alunos com deficiência intelectual. A mudança desse cenário requer uma escola inclusiva que reafirme um compromisso político, ao resgatar o saber-fazer dos métodos especiais, sem abrir mão de seu legítimo combate contra a segregação educacional e social antes praticada.

Palavras-chave: Educação Especial e Inclusiva; Pedagogia Histórico-Crítica; Alunos com Deficiência Intelectual.

BACK TO THE STICK'S CURVATURE THEORY: INTELLECTUAL DISABILITIES IN INCLUSIVE SCHOOL ABSTRACT: This article proposes a philosophical reflection about the educational inclusion of students with Intellectual Disabilities by a critical-dialectical exercise, intending to detect the contradictions of the studied phenomenon. Pedagogical concepts and practices are verified although apparently inclusive and democratic, in essence, they lead to repeatedly exclusion of these students, due to not consider their real cognitive needs, nor admit, as a necessary condition for their learning, any form of methodological or curriculum distinction. Thus, the inclusive school as it looks today is reactionary and not very democratic, while the especial school was more committed to the education of students with Intellectual Disabilities. The reversal of this scenario requires an inclusive school that reaffirms a political commitment, rescuing the know-how of the special methods, without giving up its legitimate fight against social and educational segregation practiced before.

Keywords: Especial and Inclusive Education; Historical and Critical Pedagogy; Students with Intellectual Disabilities.

* Mestrando em Educação pela Universidade Estadual de Mato Grosso do Sul (UEMS). E-mail: gio bezerra@hotmail.com * *Doutora em Educação pela Universidade Estadual de Campinas (UNICAMP); Docente Adjunta da Universidade Estadual de Mato Grosso do Sul (UEMS). E-mail: doracina@uems.br 


\section{Introdução}

A inclusão escolar de alunos com deficiência intelectual vem se desenrolando com mais vigor desde os anos 1990, quando o debate sobre o assunto começou a ser amplamente difundido por meio de organismos internacionais, como a Organização das Nações Unidas (ONU) e a Organização das Nações Unidas para a Educação, a Ciência e a Cultura (Unesco). Empenhadas em assegurar novos rumos à educação, as organizações referidas tornaram a escola supostamente inclusiva, segundo ditames do modelo neoliberal hegemônico. Em nosso país, contudo, algumas ambiguidades nos textos jurídicos motivaram um atraso significativo nesse processo, de maneira que a inserção obrigatória de crianças com deficiência intelectual em escolas regulares só tomou proporções relevantes na primeira década do século XXI, com a implantação das Diretrizes Nacionais para a Educação Especial na Educação Básica (BRASIL, 2001) e o estabelecimento definitivo de uma Política Nacional de Educação Especial, na perspectiva da Educação Inclusiva, lançada em janeiro de 2008 (BRASIL, 2008b).

Ao longo dos últimos dez anos, a proposta de inclusão escolar em nosso país passou por muitos descompassos, constituindo-se um tema polêmico e contraditório. Ao findar dessa década, no entanto, começa a tornar-se uma questão banalizada no cotidiano das escolas e, na pauta das discussões universitárias, não tem recebido a atenção adequada ao problema. Dessa forma, é de suma relevância realizar, neste final de decênio, uma análise crítica do tema e uma avaliação criteriosa da realidade da educação inclusiva no Brasil. Alguns aspectos problemáticos, não solucionados a contento no período considerado de sua implantação, foram eleitos para análise, com o respaldo metodológico do pensamento crítico-dialético, com o fito de desvendar contradições e equívocos da inclusão escolar de alunos com deficiência intelectual - um fetiche - no espaço da escola comum e da universidade, realidade que ratifica, quase sempre, a exclusão do aluno, em vez de legitimar seu combate.

Nesse sentido, acreditamos ser propício retornar ao universo da Pedagogia Histórico-Crítica e às premissas filosóficas que a fundamentam. A mediação da corrente pedagógica referida oferece-nos, sem qualquer dúvida, a possibilidade de enxergar a problemática da inclusão escolar de alunos com deficiência intelectual sob o prisma da criticidade e da 
radicalidade filosóficas. Todavia, não se deve pensar que, de nossa parte, radicalidade confunde-se com o radicalismo oportunista, tão em voga nos últimos tempos. No uso dessa expressão, esperamos que se vislumbre uma postura reflexiva, pela qual:

Em primeiro lugar, exige-se que o problema seja colocado em termos radicais, entendida a palavra radical no seu sentido mais próprio e imediato. Quer dizer, é preciso que se vá até às raízes da questão, até seus fundamentos. Em outras palavras, exige-se que se opere uma reflexão em profundidade (SAVIANI, 2004, p. 17).

Sem uma reflexão dessa natureza, todos nós, educadores ou não, corremos o risco de tomar a aparência da coisa pela sua essência (KOSIK, 2002) ou, ainda, a visão de superfície como uma visão de profundidade (E quão diferente é a superfície de um oceano de suas profundezas?!), a ponto de julgarmos certo o que, de fato, constitui-se em um lamentável engodo. É nessa perspectiva que a filosofia da educação, um instrumento de emancipação pedagógica, deve necessariamente nos auxiliar, se queremos deixar o mundo enganador e ilusório da pseudoconcreticidade para atingir a concreticidade (KOSIK, 2002). Por intermédio da atitude filosófica, podemos romper, no campo pedagógico, com "O mundo do tráfico e da manipulação, isto é, da praxis fetichizada dos homens (a qual não coincide com a praxis crítica revolucionária da humanidade)" (KOSIK, 2002, p. 15, grifo do autor), e chegar, assim, à esfera do pensamento dialético, capaz de apreender toda a polissemia do real, "[...] isto é, a sua contraditoriedade e multiplicidade de significados [...]" (KOSIK, 2002, p. 58).

Sabemos, contudo, que a passagem do mundo fenomênico para o mundo da totalidade concreta não é tarefa fácil, sobretudo em tempos em que sujeito e consciência tornam-se rarefeitos perante as artimanhas pós-modernas. No âmbito educacional, constatamos um desastroso esquecimento da reflexão filosófica e o predomínio da atitude alienante e alienada do senso comum ou daquilo que Kosik (2002) chama de praxis utilitária cotidiana. Atitude esta ainda mais sintomática no caso da inclusão escolar de alunos com deficiência intelectual, pois a ideologia do pensamento politicamente correto, não adequado, porém, à realidade concreta, tem impedido o avanço sistemático da crítica e silenciado muitos professores e pesquisadores. Uma verborragia idealista e esvaziada de sentido, "[...] retórica que, cada vez mais, nos assalta inteligência [...]" (CORREIA, 
2006, p. 240), acaba por promover julgamentos que tendem quase à estupidez e ao absurdo. Nesse contexto, resgatarmos a filosofia na prática da educação e para refletir sobre a educação é uma atitude conveniente, pois

A filosofia é uma atividade humana indispensável, visto que a essência da coisa, a estrutura da realidade, "a coisa em si", o ser da coisa, não se manifesta direta e imediatamente. Neste sentido, a filosofia pode ser caracterizada como um esforço sistemático e crítico que visa a captar a coisa em si, a estrutura oculta da coisa, a descobrir o modo de ser do existente (KOSIK, 2002, p. 17, grifo do autor).

Nosso empenho em abordar o tema em estudo sob uma perspectiva filosófica justifica-se a fim de que possamos captar o que há de suspeito e ilusório no modo como vem se efetivando a inclusão de crianças com deficiência intelectual nas escolas. Desvendar o modo de ser do existente, com o propósito de chegar a uma nova síntese ou, pelo menos, à elaboração catártica do problema é nosso objetivo maior neste trabalho. Segundo os ensinamentos de Gramsci (1995, p. 53), a catarse representa "[...] a passagem do momento puramente econômico (ou egoísta-passional) ao momento ético-político, isto é, a elaboração superior da estrutura em superestrutura na consciência [...]". Empregada na acepção dialética do termo, a catarse permite-nos atingir, finalmente, "[...] uma elaboração superior da própria concepção do real" (GRAMSCI, 1995, p. 21), bem como nos apropriar de um meio libertador de pensamento que redunde, ainda segundo o filósofo italiano (1995, p. 53), "[...] em fonte de novas iniciativas" para a práxis humana. Podemos, portanto, afirmar, tranquilamente, que a busca pela catarse, ora empreendida, representa nosso esforço em passar da consciência ingênua à consciência crítica (SAVIANI, 2000; 2003), processo a partir do qual começamos a nos distanciar de uma relação pragmática com o mundo e ousamos questionar se, de fato,

[...] é preferível "pensar" sem disto ter consciência crítica, de uma maneira desagregada e ocasional, isto é, "participar" de uma concepção de mundo imposta mecanicamente pelo ambiente exterior, [...] ou é preferível elaborar a própria concepção de mundo de uma maneira crítica e consciente e, portanto, em ligação com este trabalho do próprio cérebro, escolher a própria esfera de atividade, participar ativamente na produção da história do mundo, ser o guia de si mesmo e não aceitar do exterior, passiva e servilmente, a marca da própria personalidade? (GRAMSCI, 1995, p. 12). 
A última opção, com certeza, é a mais acertada, quando se fixa como ponto de partida e ponto de chegada a própria Pedagogia Histórico-Crítica, com a riqueza de seus fundamentos filosóficos, para análise do problema estudado. Nesse sentido, um retorno dialético à "Teoria da Curvatura da Vara" (SAVIANI, 2000) é condição sine qua non para explicitarmos, por meio da catarse gramsciana, nossa concepção crítica sobre a atual proposta de educação inclusiva. Ao adotarmos essa teoria como parâmetro teórico de nossa reflexão filosófica, situamos melhor a fixação catártica do problema.

Com base na "Teoria da Curvatura da Vara", Saviani (2000) esboça três teses fundamentais para uma compreensão crítica da educação brasileira, que apenas mencionaremos de passagem para situar o leitor, considerando não ser o objetivo de nossa análise realizar um estudo dessas teses. A primeira trata "do caráter revolucionário da pedagogia da essência e do caráter reacionário da pedagogia da existência" (SAVIANI, 2000, p. 36); a segunda propõe uma discussão em torno "do caráter científico do método tradicional e do caráter pseudo-científico dos métodos novos" (SAVIANI, 2000, p. 36) e, por fim, a terceira põe em evidência uma constatação: "[...] quando mais se falou em democracia no interior da escola, menos democrática foi a escola; e [...] quando menos se falou em democracia, mais a escola esteve articulada com a construção de uma ordem democrática” (SAVIANI, 2000, p. 36). Vale, entretanto, conferir o que vem a ser essa "Teoria" que, de acordo com Althusser (apud SAVIANI, 2000, p. 37),

[...] foi enunciada por Lênin ao ser criticado por assumir posições extremistas e radicais. Lênin responde o seguinte: "quando a vara está torta, ela fica curva de um lado e se você quiser endireitá-la, não basta colocá-la na posição correta. É preciso curvá-la para o lado oposto".

Em face da definição da "Teoria da Curvatura da Vara", poderse-á perguntar, então, em que medida essa teoria relaciona-se com nosso estudo e com nossa escolha filosófica. A explicação é simples, embora não simplista: nós a consideramos uma metáfora e uma premissa fundamental por meio da qual podemos refletir criticamente sobre a inclusão escolar de alunos com deficiência intelectual. A Educação Inclusiva apresentase, na conjuntura hodierna, como uma vara torta e curvada, deformada em razão do peso de suas ambiguidades, exigindo, portanto, a radicalida- 
de das reflexões filosóficas para endireitá-la novamente. Ocorre, entretanto, que, antes de endireitá-la, será preciso forçá-la a descrever uma trajetória em sentido oposto, até encontrar o ponto de sua negatividade: a Educação Especial, que tem sido tão criticada e condenada nesta década. De fato, ainda que soe paradoxal, haja vista que a dialética não teme as contradições, mas desenvolve-se a partir delas, é com a curvatura em direção à Educação Especial que se pode esboçar a contento um reexame da Educação Inclusiva e devolver-lhe o verdadeiro sentido, ou melhor, a direção correta.

A fim de atender a esse reexame, é necessário explicitarem-se algumas teses que funcionam como a força motriz da "curvatura". Nesse ponto, tornar-se-á evidente para nosso leitor em que sentido e em que medida a Pedagogia Histórico-Crítica e a Teoria referida vêm corroborar nossas reflexões. As teses "radicais" de Saviani (2000) serão retomadas como um referencial mediador para analisarmos a problemática da inclusão escolar de alunos com deficiência intelectual, isentando-se o autor citado de qualquer responsabilidade ou endosso sobre o uso que fazemos, neste texto, de suas ideias. Considerando que o alvo de nossa crítica é um assunto bastante específico, retomamos as duas primeiras teses com algumas adequações ao nosso objeto de estudo e mantivemos a terceira, embora a interpretação que dela fazemos seja também muito peculiar. Nossa intenção não é encontrar no posicionamento desse estudioso uma fórmula pronta e acabada ou uma resposta definitiva às nossas indagações. Em última instância, o que temos em mente, ao fundamentar nossa análise com base nessas teses, é mais o desejo de apreender na globalidade o modo como Saviani $(2000 ; 2003)$ constrói metodologicamente seu raciocínio dialético para enfocar os problemas da educação brasileira, e não apenas recorrer a citações isoladas (VIGOTSKI ${ }^{1}$, 2004) para a constituição de nosso texto. Como menciona Vigotski (2004, p. 395, grifo do autor), "O que sim pode ser buscado previamente nos mestres do marxismo não é a solução da questão, e nem mesmo uma hipótese de trabalho [...], mas o método de construção". Sendo assim, as duas primeiras teses de Saviani são adaptadas da seguinte maneira: 1) do caráter revolucionário da Pedagogia Especial e do caráter reacionário da Pedagogia de Orientação Inclusiva; 2) do caráter científico do método especial e do caráter pseudocientífico da proposta inclusiva. Cada uma dessas teses, aplicadas ao atual contexto da inclusão de alunos com deficiência intelectual nas escolas 
regulares, será devidamente explicitada a seguir com o intuito de, ao final, curvarmos a vara para o lugar certo, como o leitor poderá perceber.

\section{Apresentação da Primeira Tese: \\ do caráter revolucionário da Pedagogia Especial e do caráter reacionário da Pedagogia de Orientação Inc/usiva}

A primeira tese, como se evidencia, coloca-nos numa posição bastante polêmica, porque afirmamos o caráter revolucionário da Pedagogia Especial, enquanto qualificamos de reacionária a Pedagogia da Inclusão. Mas em que medida esse ponto de vista é possível? Não haveria nessa perspectiva um total descompasso ao que se apregoa no meio educacional? Os adjetivos não estariam invertidos? São perguntas imediatas que essa proposição suscita e que carecem de uma resposta bem-articulada, para não passarmos por opositores aos direitos humanos e avessos a uma escola de bases democráticas e inclusivas. Expliquemos, então, nosso raciocínio.

Nos últimos anos, temos pesquisado a fundo a problemática da inclusão de alunos com deficiência intelectual nas escolas comuns, inclusive analisando de perto como esse processo vem ocorrendo na prática, por meio dos relatos de professores e acadêmicos, com os quais trabalhamos frequentemente na universidade ${ }^{2}$. Nossa percepção é de que a tão propalada inclusão desses alunos tem ocorrido de forma irresponsável na escola regular, em razão de esta não saber lidar com as especificidades desses alunos, além de não reconhecer a significância das suas diferenças (CORREIA, 2006), tornando-se, assim, excludente por princípio. A inclusão acontece apenas no plano aparente do discurso, já que, na sala de aula, os alunos com deficiência intelectual não têm do professor um acompanhamento psicopedagógico que lhes permita alcançar um desenvolvimento cognitivo efetivo com a apropriação das funções psicológicas superiores e a ampliação da Zona de Desenvolvimento Proximal (VIGOTSKI, 2008).

Em nome de uma postura politicamente correta, os professores adotam uma postura politicamente incorreta ou, melhor, antidemocrática. Espera-se do aluno com deficiência intelectual as mesmas atividades realizadas pelos demais colegas e da mesma maneira, sem, entretanto, disponibilizar para ele uma intervenção metodológica apropriada. Confirma-se, 
assim, o fetiche do igualitarismo, que considera todos iguais já no ponto de partida (SAVIANI, 2000). Essa igualdade assim formulada tem nos incomodado porque, na realidade, nega a deficiência, escamoteando-a, e cumpre uma função nada louvável: a de manter o professor no imobilismo de uma práxis que permanece a mesma de antes, a mesma de sempre, a mesma para todos. Correia (2006, p. 241), um autor português, estudioso da educação inclusiva, que muito tem a contribuir para o entendimento dessa situação no Brasil, esclarece-nos que:

A retórica do igualitarismo, quando este não se vê dentro de uma perspectiva das nossas necessidades, das diferenças significativas que alguns de nós possuem, embora possa encantar e seduzir aqueles menos preparados, não passa disso mesmo: uma discussão palavrosa, pobre de ideias.

Constatamos, portanto, uma objetivação ilusória do conceito de inclusão na práxis pedagógica cotidiana. Alguns grupos radicais de educadores-pesquisadores negam peremptoriamente que alunos na condição ontogênica mencionada possam realizar, na sala de aula comum, atividades distintas dos demais alunos (MANTOAN, 2006; BATISTA; MANTOAN, 2007), pois uma distinção de atividades seria ferir uma suposta igualdade. Uma postura dessa natureza reflete uma desagradável inércia ao pressupor que o Atendimento Educacional Especializado (AEE) possa resolver, num passe de mágica, todas as dificuldades acadêmicas de um aluno com deficiência intelectual. Ledo engano. Nessas circunstâncias, o professor da sala comum nada pode fazer, senão constatar que a criança com deficiência intelectual não aprende os conteúdos curriculares, aceitando, de forma paliativa, que o objetivo da escola se resume em socializar tal aluno. Ora, é justamente porque uma criança nessa condição não está, a princípio, no mesmo nível intelectual que as demais que ela precisa de atenção individualizada da escola, que deveria oferecer, de forma gradual, atividades capazes de fazê-la avançar no domínio progressivo das funções mentais elaboradas. Somente desse modo o currículo escolar poderia lhe fazer algum sentido e não levá-la ao estresse, ao esgotamento psíquico em virtude de exigências escolares muito além de suas possibilidades imediatas. Nesse caso, as características cognitivas têm de ser consideradas, sob pena de a escola regular não cumprir o objetivo que se propôs (ou que lhe propuseram) quando passou a receber crianças com essa deficiência, ou seja, permitir-lhes o máximo desenvolvimento cognitivo e social possivel.

Educação em Revista | Belo Horizonte | v.27 | n.02 | p.277-302 | ago. 2011 
Embora haja muitos discursos pomposos em torno de um pretenso compromisso político com a inclusão, é pouca a competência técnica para torná-lo realidade (SAVIANI, 2003). Não temos receio em afirmar que a Pedagogia da Inclusão é, em sua essência, uma Pedagogia reacionária e tem contribuído muito pouco para a aprendizagem dos alunos com deficiência intelectual, pois não reconhece as necessidades particulares desses alunos ou não sabe como supri-las. $\mathrm{Na}$ realidade, alardeia-se que "[...] cabe ao aluno individualizar a sua aprendizagem [...]" (MANTOAN, 2007, p. 49) e, desse modo, este jamais “[...] deverá aprender a partir de currículos adaptados para suas necessidades, segundo a decisão do professor ou do especialista" (MANTOAN, 2007, p. 49). Como é de se esperar, numa realidade como a descrita, os alunos com deficiência intelectual ficam abandonados à própria sorte, numa situação que beira a negligência, posto que a sala regular converte-se num meio restritivo, "[...] impeditivo de uma aprendizagem com sucesso" (CORREIA, 2006, p. 265), pois esses alunos não conseguem acompanhar determinados conteúdos curriculares, pelo menos a priori. Mesmo não sendo esta a intenção original da escola, transfere-se para o educando a responsabilidade sobre seu próprio desenvolvimento intelectual, eximindo o professor da tarefa de proporlhe um programa de ensino realmente desafiador em termos cognitivos e educacionais.

As circunstâncias do aprendizado de alunos com deficiência intelectual tornam-se ainda mais complexas quando constatamos que nem todos esses alunos frequentam o AEE e, se o fazem, também não temos aí a garantia de um trabalho muito sistemático de intervenção psicopedagógica. Na realidade, esta é até negada, pois, em geral, esbarra-se numa prática de orientação subjetiva, reflexo direto da própria formação lacunar do professor especializado, bem como das recomendações divulgadas em manuais do Ministério da Educação (MEC), em parceria com a Secretaria de Educação Especial (SEESP). Nesses documentos, há uma conjunção inusitada de Psicanálise com Construtivismo piagetiano, defendendo-se tanta autonomia para os educandos atendidos no AEE, que a função mediadora e vital do especialista fica reduzida quase a nenhuma intervenção efetiva (BATISTA; MANTOAN, 2007). Com isso, cai-se num interacionismo caótico e o trabalho do educador-especialista colabora muito pouco para o desenvolvimento cognitivo dos alunos, pois, nessa perspectiva, as atividades não precisam necessariamente ser planejadas 
para estimular as funções psicológicas comprometidas ou tampouco para favorecer a apropriação e a objetivação de habilidades intelectuais cada vez mais complexas. Em última instância, defende-se que não se deve retirar do aluno "[...] a condução do seu próprio processo educativo" (MANTOAN, 2007, p. 49), atitude, entretanto, que, se avaliada com perspicácia, impede apenas que o aprendiz supere suas limitações, porquanto não pode fazêlo sozinho.

A Pedagogia Especial, diferentemente da inclusiva, voltava-se a um atendimento mais individualizado de alunos com deficiência intelectual, munida de um conjunto sólido de saberes, metodologias e práticas de ensino bem-delineados, resultantes de muitos anos de experiência direta com um público dessa natureza. O professor do ensino especial detinha maior conhecimento técnico para lidar com as dificuldades intelectuais de seus alunos e para promover neles a emergência de novas funções psicológicas superiores, mesmo que nem sempre tivesse uma consciência plena a respeito de seu know-how. Além disso, a Pedagogia Especial visava a instrumentalizar o aluno a ter cuidado consigo mesmo, bem como noções sobre vida autônoma, incluindo desde informações básicas sobre higiene, cuidados com o próprio corpo, até questões referentes a situações específicas: como frequentar estabelecimentos comerciais ou espaços sociais, bem como ter estratégias para se defender de abusos e exploração na rua, em casa e em outras situações cotidianas. As habilidades desses alunos costumavam ser reconhecidas e incentivadas por meio da realização de oficinas de artesanato, dança, culinária, entre outras. Por outro lado, as exigências curriculares vinham, de certo modo, ao encontro de suas necessidades, impedindo-os de esforço e sofrimento desnecessários.

Apenas nesse sentido, o do "saber-fazer", consideramos a Pedagogia Especial como revolucionária ${ }^{3}$, pois nela notava-se uma preocupação bem maior do professor com o modo como uma criança com deficiência intelectual se desenvolvia, posicionava-se na sociedade e aprendia, recorrendo-se, para tanto, a metodologias ou atividades adequadas e diferenciadas, uma vez que "[...] muitas das respostas para os alunos com $\mathrm{NEE}^{4}$ [para o autor, necessidades educativas especiais] requerem qualidade, estruturação e eficiência, atributos sem os quais não é possível dar resposta às necessidades diárias dos alunos com NEE" (CORREIA, 2006 , p. 265, grifo nosso). Esses saberes, lamentavelmente, foram se perdendo com o advento da inclusão, pois esta, para se afirmar, tentou repe- 
lir de seu modus operandi tudo o que remetesse à Pedagogia Especial, o que muito tem limitado o alcance do processo de ensino-aprendizagem para esses alunos, além de contribuir para se criar um clima de desilusão e confusão em volta do movimento pela escola inclusiva (CORREIA, 2006). Ampliemos, pois, nossas discussões sobre o tema, demonstrando a segunda tese, decorrente da primeira.

\section{Apresentação da segunda Tese: do caráter científico do método especial $e$ do caráter pseudocientífico da proposta inclusiva}

A segunda tese leva-nos a refletir mais a fundo sobre o problema da competência técnica (SAVIANI, 2003) em Pedagogia, isto é, a importância daquele saber-fazer que procuramos demonstrar. Quando enunciamos anteriormente que a Pedagogia Especial apresenta um caráter científico em sua metodologia, ao passo que a proposta inclusiva adota uma postura pseudocientífica, não estamos sendo levianos, mas indo à essência da questão. Ao acompanharmos os caminhos e descaminhos da Pedagogia de Orientação Inclusiva ao longo desta primeira década do século XXI, conforme mencionamos na Introdução, constatamos a prevalência quase absoluta do espontaneísmo na forma como essa pedagogia é conduzida nas escolas regulares, confirmando, assim, a ausência de conhecimentos científicos e sistemáticos sobre a maneira de conduzir o ensino de crianças com deficiência intelectual. Esquece-se de que os alunos nessa condição precisam necessariamente de metodologias e recursos específicos (VYGOTSKI, 1997), pois, do contrário, torna-se bastante difícil permitir-lhes, pelo menos em parte, a apropriação do saber elaborado. Como nos lembra Vygotski (1997, p. 34, grifo do autor), "[...] precisamente para que el niño deficiente pueda lograr lo mismo que el normal, corresponde utilizar medios absolutamente especiales". Indo um pouco mais longe, o autor citado insiste em uma verdade que, embora possa soar inconveniente para muitos de nós, educadores, nem por isso deixa de ser legítima e necessária. Com base nas palavras de Vygotski (1997, p. 81), é possível esclarecer que 
No negamos la necesidad de la educación y la enseñanza especiales de los niños deficientes. Por el contrario, afirmamos que la enseñanza de la lectura a los ciegos o del lenguaje oral a los sordomudos demanda una técnica pedagógica especial y recursos y métodos especiales de los niños deficientes [o mesmo vale, evidentemente, para a deficiência intelectual, objeto deste estudo]. Y sólo el conocimiento científico de la técnica puede formar un auténtico pedagogo en este terreno.

Tais considerações, porém, têm sido ignoradas pelos defensores da Pedagogia da Inclusão, que se recusam a assumir uma postura coerente com as demandas cognitivas dos educandos com deficiência intelectual. Cada vez mais, perdem de vista o papel mediador do professor, isto é, sua função precípua de conhecer as peculiaridades da ontogênese infantil para direcionar corretamente o desenvolvimento cognitivo da criança, recorrendo, se preciso for, a estratégias individualizadas de ensino, adequadas para compensar as limitações impostas pela própria deficiência ${ }^{5}$ (VYGOTSKI, 1997). Dessa forma, a proposta inclusiva esvazia-se, dissolve-se na fraseologia romântica que profetiza uma suposta beleza do convívio com as diferenças, sem avançar, contudo, na pesquisa, na proposição e na sistematização de informações relevantes para o encaminhamento da práxis pedagógica. $\mathrm{Na}$ realidade, não há sequer um referencial epistemológico definido que subsidie o trabalho dos professores no cenário da proposta inclusiva, mas, ao contrário, impera um ecletismo caricato. Para termos uma ideia da situação, reproduzimos a seguir mais um trecho, a nosso ver sintomático do problema, disposto numa das cartilhas do Ministério da Educação:

O professor, na perspectiva da educação inclusiva, não ministra um "ensino diversificado" e para alguns. Ele prepara atividades diversas para seus alunos (com ou sem deficiência mental) ao trabalhar um mesmo conteúdo curricular. Essas atividades não são graduadas para atender a níveis diferentes de compreensão e estão disponíveis na sala de aula para que os alunos as escolham livremente, de acordo com seus interesses. (BATISTA; MANTOAN, 2007, p. 17-18)

Nesse fragmento, há um jogo capcioso de palavras, que seduz pela aparência, mas está comprometido na sua essência: ao trazer atividades diversas, já não estaria o professor ministrando, pelo menos em algum momento, um ensino diversificado e individualizado, posto que cada uma 
dessas atividades, escolhidas pelos alunos, demandaria do docente posturas metodológicas bastante distintas entre si? Não que consideremos isso um total equívoco, já que defendemos um ponto de vista semelhante em nosso texto, mas chamamos a atenção para o beco sem saída no qual se encontra enrodilhada a proposta da educação inclusiva em nosso país, que se perde em suas próprias divagações. Outro ponto digno de menção nesse excerto refere-se à prerrogativa segundo a qual se delega ao próprio educando a escolha de sua atividade. Não estaria nesse privilégio uma herança malévola e pseudocientífica do Construtivismo, aliada a alguns resquícios de Escola Nova? Se a escola prima pela transmissão do saber objetivo (SAVIANI, 2003), visando à emergência das funções psicológicas superiores no educando, pela mediação de sujeitos mais experientes (VIGOTSKI, 2008), como conceber uma postura dessa natureza? Não seria esta uma atitude espontaneísta que desconsidera, a priori, o fato de que é o professor quem deve saber por onde e para onde direcionar a aprendizagem infantil? Tal atitude acaba, sem o querer, justificando um descompromisso com as crianças com deficiência intelectual, que precisam com urgência de uma escola competente não só politicamente, mas tecnicamente, ou seja, de uma escola apta a perceber que "[...] o aprendizado adequadamente organizado resulta em desenvolvimento mental e põe em movimento vários processos de desenvolvimento que, de outra forma, seriam impossíveis de acontecer" (VIGOTSKI, 2008, p. 103, grifo nosso). Em outras palavras, falta à demagogia da inclusão clareza e métodos suficientes para compreender que "A educação é o domínio artificial dos processos naturais de desenvolvimento" da criança (VIGOTSKI, 2004, p. 99), cabendo, portanto, ao professor demonstrar competência técnica para exercer esse domínio.

Pelo exposto, demonstramos a pseudocientificidade da Pedagogia Inclusiva. Em contraponto, a Pedagogia Especial apresentou-se com base em métodos e sua prática baseou-se sempre em resultados de estudos psicológicos e clínico-neurológicos, ainda que tais estudos partissem, na maioria das vezes, de premissas negativas ou estereotipadas, levando mesmo a uma série de equívocos teórico-práticos. Nesse caso, interessanos, porém, ressaltar a presença de uma intencionalidade e uma diretividade maiores do fazer pedagógico, hoje quase inexistentes com o advento da filosofia inclusiva. Esta última apregoa que "[...] cabe ao aluno individualizar a sua aprendizagem [...]. O ensino individualizado, adaptado 
pelo professor, [...] implica em intervenções e escolhas do professor, que passa a controlar de fora o processo de aprendizagem" (MANTOAN, 2007, p. 49). Mas não é esse o trabalho do professor competente? Não é ele quem deve conduzir de maneira sistemática a atividade da criança para levá-la à internalização dos meios culturais de pensamento e ao domínio dos conceitos científicos? Há, portanto, uma dose exacerbada de Construtivismo nessa filosofia, descaracterizando o papel ontológico do professor e da Pedagogia como ciência. Igualmente, não poderíamos desconsiderar ainda, na apresentação da segunda tese, o fato de que muitas formulações científicas com grande valor para a práxis educacional contemporânea foram se constituindo, ao longo de muitos anos, no campo da pesquisa e da prática em educação especial. Obtiveram-se dessa experiência técnicas, conceitos e saberes - teoricamente sistematizados e praticamente validados - que, hoje, são negligenciados. Em virtude dessa constatação, enunciamos com tranquilidade a segunda tese, qualificando de científico o método especial e de pseudocientífica a proposta, e não um método, inclusiva.

\section{Terceira Tese:}

"de como, quando mais se falou em democracia no interior da escola menos democrática foi a escola; $e$ de como, quando menos se falou em democracia, mais a escola esteve articulada com a construção de uma ordem democrática" (SAVIANI, 2000, p. 36)

A terceira tese decorre das anteriores e tem um fundamento especificamente político (SAVIANI, 2000), pois questiona a existência concreta da democracia nas instituições escolares. Fundamentados por essa tese, podemos avaliar que a hegemonia do discurso sobre a inclusão elege a democracia como a palavra de ordem na escola regular. Fala-se o tempo todo de uma escola pluralista que se abre às diferenças, às deficiências e que, de maneira nobre, oferece as mesmas oportunidades para todos os alunos, sem distinção alguma, respeitando os direitos humanos mais fundamentais. Todos, na escola inclusiva, são iguais e qualquer diferenciação feita é considerada perigosa e inconciliável com uma atitude democrática. Nessa perspectiva, acionam-se mecanismos jurídicos e ideológicos que normalizam a diferença, até quase apagá-la por completo no 
cotidiano escolar, porque é preciso outorgar aos indivíduos a "[...] prerrogativa da condição cidadã, que implica uma vida comunitária cada vez mais próxima dos ideais democráticos de convívio social, liberdade e participação nas decisões políticas" (MANTOAN, 2006, p. 184-185). Antes de uma possível estranheza do leitor, ressaltamos que nada haveria de problemático nesse posicionamento, não fosse o vício neoliberal que o perpassa de ponta a ponta e faz da igualdade mais um fetiche da retórica pósmoderna (CORREIA, 2006). A consequência dessa postura, na perspectiva inclusiva, é que as escolas comuns precisam ensinar os alunos com Deficiência Intelectual, mas “[...] sem trabalhar à parte com alguns alunos, sem estabelecer regras específicas para planejar, aprender e avaliar (currículos, atividades, avaliação de aprendizagem para alunos com deficiência e necessidades educacionais especiais)" (MANTOAN, 2006, p. 196).

Ora, esse discurso normalizador da diferença, se foi revolucionário no princípio desta década, quando se buscava combater a todo custo o preconceito em relação às pessoas com deficiência, sobretudo aquelas com deficiência intelectual, no final dessa mesma década deixou de sê-lo, revelando-se excludente e perverso exatamente para alunos com alguma deficiência. Por isso, insistimos na análise crítica da questão. Entendemos que esse tratamento igualitarista aos alunos com limitações intelectuais na escola comum, ao ser levado às últimas consequências, não só cerceia-lhes o direito ao pleno exercício da cidadania, como tende a prejudicar seu desenvolvimento cognitivo e social. Nesse mundo de pseudoconcreticidade, condena-se qualquer tentativa de diferenciação curricular e metodológica, esquecendo-se que, muitas vezes, isso é uma prática é sine qua non para o verdadeiro progresso acadêmico do aluno. A escola inclusiva, para não ser discriminatória, acaba, por conseguinte, desconsiderando as reais necessidades dos alunos com deficiência intelectual, homogeneizando-os, e legitimando uma postura antidemocrática, embora, na aparência, seu discurso seja democrático. Nesse sentido, estamos de acordo com Correia (2006), quando este, após sugerir mais rigor na caracterização dos alunos com necessidades educacionais especiais e demonstrar a importância de proporcionar-lhes acesso a um programa educacional específico, afirma o que se segue:

Se essas premissas não forem consideradas, então estou convicto de que não só desrespeitamos os direitos do aluno, como também poderemos entregá-lo a um insucesso tal que, mais tarde, virá a refletir-se em uma inserção social e 
laboral deficitárias. O processo de cidadania, objeto primeiro da educação, deixa, assim, muito a desejar (CORREIA, 2006, p. 250).

Não restam dúvidas, portanto, de que quanto mais se fala em democracia e inclusão na escola, menos democrática e inclusiva é a escola em razão de uma premissa errada: condiciona-se a princípio todos os alunos à igualdade e recusa-se a flexibilização de currículos. Para os educandos com deficiência intelectual, o resultado pode ser o insucesso tanto na vida escolar quanto na vida social mais ampla. Em diversos momentos, esses alunos precisam de atendimento específico e diferenciado na sala de aula e na escola comum para que, com o desenrolar das mediações pedagógicas apropriadas, estejam justamente numa condição educacional e psíquica bem próxima da situação dos demais alunos, isto é, daqueles sem deficiência. É muito válido e oportuno resgatarmos a esta altura algumas reflexões de Saviani (2000) que, apesar de serem direcionadas às artimanhas da Escola Nova, podem servir para revermos a proposta da Escola Inclusiva. No dizer de Saviani (2000, p. 77),

[...] se a democracia supõe condições de igualdade entre os diferentes agentes sociais, como a prática pedagógica pode ser democrática já no ponto de partida? Com efeito, se [...] a educação supõe a desigualdade no ponto de partida e a igualdade no ponto de chegada, agir como se as condições de igualdade estivessem instauradas desde o início não significa, então, assumir uma atitude pseudodemocrática? Não resulta, em suma, num engodo?

Sob essa perspectiva, podemos confirmar a contradição em que resulta a prática escolar ancorada pelo ideário da inclusão, que se fundamenta por uma visão pseudodemocrática. A Escola Especial, ao contrário, não se supunha democrática e nem fazia questão de aparentar-se democrática. Contudo, uma análise dialética de seu projeto permite-nos ver no seu âmago uma ação pedagógica muito mais democrática e coerente do que aquela que se verifica nas escolas atuais. A Escola Especial, salvo algumas exceções, conseguia dar respostas e suporte mais eficazes para estimular a aprendizagem e o desenvolvimento sociocognitivo dos alunos com deficiência intelectual. Ela contava com um vasto conhecimento técnico-empírico adequado para deflagrar com sucesso sua prática educacional, experiência que, a nosso ver, ainda não foi conquistada nem mesmo pelo AEE, forma atual de atendimento especializado, com a responsabi- 
lidade exclusiva de apoiar a inclusão de alunos com alguma deficiência na escola regular, antevendo e suprindo os apoios necessários para cada caso (BRASIL, 2008a).

Assim, é possível deduzir que a Escola Especial, ao ter no centro de suas preocupações imediatas "As necessidades complexas apresentadas por estes alunos nas áreas de comunicação, relacionamento interpessoal, vida independente, cuidados pessoais, interação e convivência social [...]" (ASSOCIAÇÃO DE PAIS E AMIGOS DOS EXCEPCIONAIS, 2008, p. 10), demonstrava, em relação ao educando com deficiência intelectual, estar mais compromissada com o oferecimento de apoios educacionais e condições equânimes de cidadania do que a escola inclusiva que ora temos. Desse ângulo, e apenas desse ângulo, nossa análise sugere que no momento em que menos se pensou em democracia na escola, a esta altura qualificada pelo adjetivo especial, mais democrática foi essa escola, pois mais atenta esteve aos direitos humanos, embora, nesse trajeto, tenha caminhado para um paradoxo condenável, ao levar ao extremo seu caráter isolacionista, assistencialista, terapêutico e mecanicista, que nos apressamos em repudiar.

Logo, uma solução ideal que atenda aos alunos com deficiência intelectual não pode ser encontrada, de imediato, na Escola Especial, pois esta, a despeito das contribuições que nos lega, também é perpassada por equívocos e vícios nefastos, que impedem uma educação transformadora, crítica e inclusiva na essência. Se viemos argumentando a favor da curvatura da vara para o lado da Escola Especial, da Pedagogia e dos métodos especiais, certamente não foi, e nem poderia sê-lo, para apregoar um retorno a esse tipo de instituição, mas tão somente para relembrar a importância teórico-prática dos saberes e metodologias acumulados por essa experiência escolar. Além disso, a curvatura da vara foi necessária para sugerir o quanto a aparência do fenômeno pode dissimular outra realidade, levando-nos a defender certos posicionamentos sem uma reflexão filosófica consistente, a ponto de, em vez de incluirmos as pessoas com deficiência, acabarmos por excluí-las ou limitar sua aprendizagem, sem ser esta a intenção que nos move. Em nome de um suposto compromisso político, repetido e disseminado com alarde por organismos internacionais mal-intencionados, esquecemos a competência técnica em educação, bem como esquecemos que "O método é essencial ao processo pedagógico” (SAVIANI, 2003, p. 75), pois é com base nele que se objetiva um 
autêntico compromisso político e, por meio dele, socializamos o saber elaborado para as novas gerações (SAVIANI, 2003).

Num cenário de ilusões e ilusionismos, os alunos com deficiência intelectual são recebidos em escolas comuns, mas nada sabemos sobre a maneira singular de ensiná-los e de proporcionar-lhes o domínio efetivo de novas competências cognitivas. $\mathrm{Na}$ esfera da pseudoconcreticidade, porém, estão sendo incluídos. Num paralelo ousado com o trabalho de Saviani (2003), tal situação nos leva a crer que estivemos, ao longo desta década, vivendo ainda a fase romântica da Inclusão, de sorte que, ao projetarmos nossas expectativas para o novo decênio, é mister atingirmos a fase clássica, "[...] encontrando nos fins a atingir [neste caso, uma educação verdadeiramente inclusiva e democrática] a fonte para a elaboração das formas adequadas de realizá-lo" (SAVIANI, 2003, p. 63). Para tanto, devemos avançar em nossa crítica a fim de recuperarmos para a vara um ponto de equilíbrio.

\section{A vara encontra seu equilíbrio}

Depois de analisarmos a Pedagogia Inclusiva e a Pedagogia Especial com base nas três teses anteriores, pelas quais a questão foi tratada em termos catárticos, precisamos superar as antíteses e chegar à síntese, pois "o processo catártico coincide com a cadeia de sínteses que resultam do desenvolvimento dialético" (GRAMSCI, 1995, p. 53). Nesse sentido, consideramos que o ponto de equilíbrio da vara não está em nenhuma das duas "pedagogias". Ao curvarmos a vara para o lado oposto à proposta da Inclusão, pretendemos fazê-la encontrar a direção correta (SAVIANI, 2000), que, com certeza, não está também na Pedagogia Especial, mas sim na valorização do saber-fazer e do legado dessa pedagogia, que, tomando de empréstimo uma expressão de Saviani (2000, p. 57), “[...] apontam para uma pedagogia revolucionária". Assim, entendemos que a Inclusão escolar de alunos com deficiência intelectual trata-se de uma conquista irrevogável e imprescindível para o desenvolvimento psicossocial desses educandos, além de representar os anseios nacionais e globais pela construção de uma sociedade mais justa, consciente dos direitos humanos fundamentais. Ocorre que esse processo tem sido feito de maneira leviana e fetichizada no contexto escolar, considerando-se, em 
outra aproximação com as ideias de Saviani (2000), a Pedagogia Especial como detentora de todos os vícios e defeitos, enquanto à proposta inclusiva atribuem-se todas as virtudes e nenhum defeito. Por isso, tivemos de demonstrar o oposto, provando que não é essa a verdade absoluta, inquietando o leitor com o propósito de fazê-lo realizar também a sua catarse.

Com efeito, a Pedagogia da Inclusão tem muito a ganhar se suprimir de seu ideário um discurso radical que, para contrapor-se à herança negativa dos métodos especiais, tem rejeitado severamente o uso estratégico de atividades diferenciadas e flexibilizações curriculares na sala comum, deixando de lado a herança positiva da Escola Especial. Entendemos que o emprego desses recursos metodológicos ofereceria uma possibilidade para se viabilizar com mais competência a aprendizagem daqueles alunos: uma forma precisa de responder às suas necessidades concretas e aos seus direitos, em vez de deixá-los na classe à mercê de suas dificuldades, numa posição de eternos espectadores. Evidentemente, não pretendemos propor uma adaptação curricular medíocre e facilitadora, mas sim assegurar aos alunos com deficiência intelectual a realização de atividades específicas e bem planejadas que tenham por objetivo a maximização de seu potencial cognitivo (CORREIA, 2006), levando-os a um ganho psicológico significativo, em vez da permanência sem sentido na escola regular, como temos visto e precisamos denunciar com este artigo.

Em condições adequadas, o professor, seja da sala comum ou especializada, precisa de muito conhecimento técnico, pois “[...] é totalmente necessário que o professor saiba de forma concreta e rigorosa para quais canais deve desviar as tendências naturais da criança [...]" (VIGOTSKI, 2003, p. 177), encontrando vias compensatórias para mediar e promover o desenvolvimento infantil marcado pela deficiência (VYGOTSKI, 1997). Ademais, torna-se fundamental que a relação entre a Pedagogia Especial e a Pedagogia Inclusiva não seja de absoluta oposição, mas de síntese, de partilha de saberes e metodologias, de vinculação dialética entre uma e outra. Assim se alcançaria o encontro entre a competência técnica e o compromisso político da inclusão, o equilíbrio metafórico da vara, seu ponto de maior estabilidade, pelo qual percebemos "[...] a importância de não se subtraírem os serviços e apoios de educação especial à esfera das práticas educativas que a filosofia inclusiva proclama" (CORREIA, 2006, p. 246). Há que se aceitar certa diferença no ponto de partida entre alunos com e sem deficiência intelectual, para se alcançar a 
igualdade possível entre eles no ponto de chegada. Se não admitirmos essa possibilidade, a prática pedagógica, a despeito de pensar-se inclusiva, termina por ser reacionária, conservadora e pouco eficaz exatamente para os educandos com deficiência dessa natureza, restringindo-lhes as oportunidades de acesso ao currículo escolar e à plena cidadania.

Não há, portanto, qualquer discriminação no que acabamos de afirmar. Antes, existe uma busca para tornarmos a proposta inclusiva revolucionária e coerente não só na aparência, mas, sobretudo, na essência, resgatando-se para ela o que havia de legítimo e sistemático nos métodos especiais para o ensino de pessoas com deficiência intelectual. Ao mesmo tempo em que se atacam os discursos alienantes ainda em voga, capazes de negar até mesmo o valor da interferência docente nos rumos do processo pedagógico, reafirmam-se as críticas contra os aspectos inegavelmente excludentes das práticas especiais de ensino. Esse é, pois, o meio legítimo para vislumbrarmos uma práxis educacional realmente inclusiva nas próximas décadas do século XXI, capaz de responder com eficácia pedagógica e com justiça social aos anseios dos alunos com deficiência intelectual. Somos da mesma opinião de Correia (2006, p. 272), quando, com muita propriedade, observa que:

[...] é preciso pensar melhor a educação, retirando-lhe a retórica que o pósmodernismo parece ter adotado, para que os alunos com NEE possam experimentar o sabor do sucesso. É preciso, portanto, que todos nós percebamos melhor as complexidades da vida escolar na sala de aula, especialmente quando eles afetam o dia-a-dia dos alunos com NEE. Para estes alunos, as consequências que emanam de pensamentos indigentes sobre o que deve ser sua educação são, de modo geral, particularmente desastrosas.

Em outras palavras, isso nos coloca diante da urgência de se desenvolver uma proposta pedagógica que tenha como premissa básica o conhecimento desmistificado da deficiência intelectual, tanto na sua dimensão psicológica quanto educacional, de modo a se promover a superação do sentimentalismo indulgente. Nesse trabalho, há que existir um intenso diálogo intrainstitucional, fundamentado na troca de informações e posturas metodológicas entre professores das salas de aula comum e professores da sala de recursos multifuncionais, esta última o lócus privilegiado do AEE no ambiente escolar, bem como o fortalecimento da comunicação interinstitucional, o que pressupõe uma aproximação sem 
preconceitos entre a escola regular e as diversas instituições especializadas, porquanto estas últimas dispõem de um acervo considerável de materiais, técnicas e recursos específicos para a intervenção psicopedagógica e a estimulação cognitiva de crianças com a deficiência abordada.

No universo das escolas comuns, tal acervo precisa, evidentemente, ser ressignificado como um apoio para subsidiar práticas verdadeiramente inclusivas e enriquecer as possibilidades da ação docente. Já os centros de Educação Especial, inspirados pelo movimento da inclusão escolar e social, podem, por sua vez, repensar a dinâmica de seu funcionamento, tornando-se espaços menos segregadores e paternalistas. Dessa feita, concretiza-se uma rica interface de saberes entre as instituições especiais e as escolas comuns.

Ao longo desse processo, é fundamental o aprofundamento teórico por parte dos educadores e pesquisadores, com vistas a se passar do conhecimento sincrético e superficial sobre o assunto para o conhecimento sintético e totalizante (SAVIANI, 2000). Essa reflexão nos leva a ressaltar a pertinência das contribuições de Vygotski (1997) para a proposição de metodologias capazes de imprimir vitalidade e êxito à inclusão escolar que ora se desenrola em nosso país. O estudo consequente de sua obra, lamentavelmente corrompida pelas interpretações construtivistas, pode enfim levar-nos a planejar e a praticar uma proposta de Educação Inclusiva inovadora, competente tanto técnica e praticamente, quanto teórica e politicamente (SAVIANI, 2003). Anunciando em linhas gerais os contornos futuros dessa práxis, segundo a perspectiva de Vygotski (1997), parece-nos que o caminho começa a ser delineado quando buscamos um enfoque positivo e dinâmico dos alunos com deficiência intelectual. Dito de outra maneira, isso nos leva a compreender que tal deficiência é um processo, não a soma imutável de funções psíquicas subdesenvolvidas. Assim, mesmo diante de uma série de limitações, existem habilidades que, com a mediação pedagógica, podem se tornar o ponto de partida para a emergência e a constituição de processos mentais qualitativamente superiores.

Nessa direção, o primeiro passo a ser dado pelos educadores, na busca por diretrizes mais claras no encaminhamento de seu trabalho, é esboçar algumas estratégias pedagógicas para responder às seguintes questões: O que a criança com Deficiência Intelectual pode fazer, isto é, quais são as vias compensatórias aptas a orientar o seu processo educativo? 
Quais funções psicológicas superiores estão preservadas e quais estão comprometidas? A partir dos resultados dessa avaliação inicial, há que se passar, então, ao momento da instrumentalização docente, quando o professor, interrogando-se sobre daquilo de que a criança com deficiência precisa para se desenvolver no contexto da escola regular inclusiva, promove a organização intencional e sistemática de atividades, recursos didáticos e metodologias que possam ampliar significativamente as possibilidades de desenvolvimento cognitivo para essa criança e para os demais alunos da classe. Não se trata, porém, de transformar a sala de aula comum em outro ambiente especializado, mas sim de torná-la um espaço de interação social onde a singularidade humana não é negada, nem escamoteada; antes, torna-se o eixo unificador que democratiza a escola e dá sentido para o desencadeamento eficaz da ação pedagógica na coletividade escolar, sem perder de vista o essencial protagonismo dos professores e as circunstâncias concretas nas quais este se realiza.

\section{Considerações finais}

Chegamos ao final deste texto e, como o leitor deve ter percebido, fizemos certo esforço filosófico ou, em linguagem kosikiana, um détour, para sairmos da aparência e adentrarmos na essência de um fenômeno bem contraditório: a inclusão escolar de alunos com deficiência intelectual. Nesse détour, fomos buscar na Pedagogia Histórico-Crítica uma referência séria para evidenciarmos alguns equívocos que têm comprometido o sucesso da proposta inclusiva em nosso país, como a negação do papel mediador do professor, associada a um descaso com os saberes legados da Pedagogia e da Escola Especiais, como se estes nada mais nos ensinassem. Em tal contexto, o problema da diferenciação curricular foi abordado, considerando-se tal prática não só como democrática e legal, mas também como absolutamente necessária para possibilitar o pleno desenvolvimento cognitivo do educando com deficiência intelectual, desde que assumida com o devido rigor metodológico e conhecimento de causa.

Sabemos que o caráter polêmico adotado ao longo de nosso texto pode ter causado, de início, certa restrição ao nosso ponto de vista, mas também acreditamos que uma leitura atenta pode dissipar julgamen- 
tos apressados, sobretudo quando se considera o pensamento dialético em torno do qual este artigo se estrutura, negando o óbvio e afirmando o inesperado para provocar o leitor e levá-lo conosco a uma jornada catártica, para, assim, chegarmos a uma síntese válida, depurada dos elementos negativos e enriquecida pelos elementos positivos, ambos arrolados durante a exposição das teses acima discutidas. Valemo-nos, então, de uma radicalidade filosófica inquietante, mas fundamental para denunciarmos a exclusão existente dentro daquilo considerado por muitos como o ápice da proposta de uma Pedagogia inclusiva. A mediação da filosofia revelou-se, portanto, imprescindível para embasar nosso raciocínio, abrindo-nos os olhos perante as ambiguidades e ambivalências nefastas da pseudoconcreticidade. Com certeza, o meio de atingirmos a concreticidade não é outro senão adotarmos essa postura radical perante a realidade, até o limite em que ela perde suas máscaras ou as águas tornam-se claras, numa alusão à metáfora do oceano. Agindo dessa maneira, nós, educadores, deixamos de ser manipulados por discursos sedutores, nem sempre os mais revolucionários, os mais justos e os mais compromissados tanto técnica quanto politicamente, e podemos ser livres, enfim, para escolhermos a marca de nossa própria personalidade e nosso lugar na história, como disse Gramsci em passagem já citada.

Ainda no rol dessas considerações, vale ressaltar que não tivemos, em momento algum, a intenção de desqualificar este ou aquele autor, esta ou aquela instituição, mas sim o objetivo de criticar certas posturas e práticas que não podemos mais aceitar, com base nos pressupostos da Pedagogia Histórico-Crítica e em nossa vivência como pesquisadores e autores de nossa história. Temos visto a inclusão se converter em exclusão, em negligência com os alunos com deficiência intelectual, diante do desconhecimento de suas peculiaridades cognitivas e em decorrência de um pretenso tratamento igualitário que cerceia, entretanto, a emergência de uma práxis inclusiva revolucionária e competente.

Nesse sentido, concluímos lembrando que nem toda diferenciação é excludente, como nem toda igualdade é, de fato, inclusiva: lição que devemos levar para os próximos decênios deste século, se quisermos avançar com seriedade e sensatez na proposta de inclusão escolar, sem repetir os erros da década que ora se despede. Para isso, entendemos ser estratégica a procura constante pela reflexão filosófica, como uma forma de direcionar a nossa caminhada como educadores, rompendo-se a bruma 
que esconde "a coisa em si" e a dissimula cotidianamente. Além disso, precisamos pensar também na urgente ampliação da competência teóricoprática do professor, para tornar sua ação realmente democrática, consciente e eficaz, sobretudo, para os alunos com deficiência intelectual. Esta é, portanto, a grande tarefa criativa que temos pela frente, inadiável, como as ondas do mar. 


\section{REFERÊNCIAS}

ASSOCIAÇÃO DE PAIS E AMIGOS DOS EXCEPCIONAIS - APAE. Posicionamento do Movimento Apaeano em defesa da inclusão escolar de pessoas com deficiências intelectual e múltipla. Ofício Circular n. 113/08: Centro Educacional Paranaibense - CEP, 29 de julho de 2008. BATISTA, C. A. M.; MANTOAN, M. T. E. Atendimento Educacional Especializado em Deficiência Mental. In: GOMES, A. L. L. et al. Atendimento Educacional Especializado: Deficiência Mental. São Paulo: MEC/SEESP, 2007.

BRASIL. Decreto n. 6.571, de 17 de setembro de 2008a. Dispõe sobre o atendimento educacional especializado, regulamenta o parágrafo único do art. 60 da Lei n. 9.394, de 20 de dezembro de 1996, e acrescenta dispositivo ao Decreto n. 6.253, de 13 de novembro de 2007. Disponível em: <http://www.planalto.gov.br/ccivil_03/_Ato20072010/2008/Decreto/D6571.htm>. Acesso em: 13 jan. 2010.

BRASIL. Ministério a Educação. Lei de Diretrizes e Bases da Educação Nacional. LDB 9.394, de 20 de dezembro de 1996.

BRASIL. Ministério a Educação. Secretaria de Educação Especial. Diretrizes Nacionais para a Educação Especial na Educação Básica. Brasília: MEC/SEESP, 2001.

BRASIL. Ministério da Educação. Política Nacional de Educação Especial na Perspectiva da Educação Inclusiva, de janeiro de 2008b. Disponível em: < http://portal.mec.gov.br/arquivos/pdf/politicaeducespecial.pdf. $>$. Acesso em: 29 jul. 2010.

CORREIA, L. de M. Dez anos de Salamanca, Portugal e os alunos com necessidades educativas especiais. In: RODRIGUES, D. (Org.). Inclusão e Educação: doze olhares sobre a educação inclusiva. São Paulo: Summus, 2006.

GRAMSCI, A. Concep̧cão dialética da história. 10 ed. Rio de Janeiro: Civilização Brasileira, 1995.

KOSIK, K. Dialética do Concreto. 7 ed. Rio de Janeiro: Paz e Terra, 2002.

MANTOAN, M. T. E. Educação Inclusiva: Orientações Pedagógicas. In: FÁVERO, E. A. G.; PANTOJA, L. M. P.; MANTOAN, M. T. E. Atendimento Educacional Especializado: Aspectos Legais e Orientações Pedagógicas. São Paulo: MEC/SEESP, 2007.

MANTOAN, M. T. E. O direito de ser, sendo diferente, na escola. In: RODRIGUES, D. (Org.). Inclusão e Educação: doze olhares sobre a educação inclusiva. São Paulo: Summus, 2006.

SAVIANI, D. Educação: do senso comum à consciência filosófica. 15 ed. Campinas: Autores Associados, 2004.

SAVIANI, D. Escola e Democracia. 33 ed. Campinas: Autores Associados, 2000.

SAVIANI, D. Pedagogia Histórico-Crítica: primeiras aproximações. 8 ed. Campinas: Autores Associados, 2003.

VIGOTSKI, L. S. A formação social da mente: o desenvolvimento dos processos psicológicos superiores. 7 ed. São Paulo: Martins Fontes, 2008.

VIGOTSKI, L. S. O desenvolvimento psicológico na infância. São Paulo: Martins Fontes, 2003. VIGOTSKI, L. S. Teoria e Método em Psicologia. 3 ed. São Paulo: Martins Fontes, 2004.

VYGOTSKI, L. S. Obras escogidas V: fundamentos de defectología. Madrid: Visor, 1997. 
1 Nas fontes pesquisadas, o nome desse autor aparece escrito com algumas variações. Por isso, mantém-se, neste texto, sempre a grafia original, tal como consta na publicação mencionada, em vez de se adotar uma padronização.

2 Com o apoio financeiro da universidade em que atuam, os autores deste trabalho já desenvolveram, em sua cidade, um projeto de extensão com vistas a proporcionar subsídios teóricos e metodológicos sobre a inclusão escolar de alunos com Deficiência Intelectual para acadêmicos de Pedagogia dessa mesma universidade e para alguns professores da rede pública de ensino. Além disso, a coautora deste artigo coordenou recentemente outro projeto de extensão, subvencionado pelo MEC, em que se discutia a dialética entre exclusão e inclusão social no cenário educacional brasileiro, atendendo um público semelhante. Assim, muitas das reflexões ora desenvolvidas resultam de nosso trabalho na universidade, o que tem nos permitido captar a totalidade concreta (KOSIK, 2002).

3 Por certo, não falamos aqui de qualquer Pedagogia Especial, mas daquela que era e é praticada em instituições sérias, com o devido rigor metodológico e corpo docente bempreparado. Não defendemos também o caráter segregador e protecionista adotado por algumas dessas instituições e seus profissionais, como se verá. Estamos apenas encaminhando um raciocínio dialético radical, a fim de curvar "a vara" para o devido lugar.

4 Em Portugal, o uso da expressão necessidades educacionais especiais parece ainda persistir, enquanto no Brasil já se encontra banido das publicações oficias recentes (BRASIL, 2008a).

$\mathbf{5}$ Lembramos que a legislação educacional vigente não condena, em momento algum, a flexibilização metodológica ou as adaptações curriculares na classe comum, quando se trata de alunos com deficiência (BRASIL, 1996; 2001), embora as cartilhas do MEC insistam em esquecer esse aspecto clarividente da legislação.

Recebido: 01/09/2010

Aprovado: 19/01/2011

Contato:

Universidade Estadual de Mato Grosso do Sul Avenida Vereador João Rodrigues de Mello, s/n. Jardim Santa Mônica CEP 79500-000 Paranaiba, MS Brasil 